\title{
On the link between Amazonian forest properties and shallow cumulus cloud fields
}

\author{
R. H. Heiblum ${ }^{1}$, I. Koren ${ }^{1}$, and G. Feingold ${ }^{2}$ \\ ${ }^{1}$ Department of Earth and Planetary Sciences, Weizmann Institute, Rehovot 76100, Israel \\ ${ }^{2}$ NOAA Earth System Research Laboratory (ESRL), Chemical Sciences Division, Boulder, Colorado 80305, USA
}

Correspondence to: I. Koren (Ilan.Koren@weizmann.ac.il)

Received: 15 October 2013 - Published in Atmos. Chem. Phys. Discuss.: 15 November 2013

Revised: 28 April 2014 - Accepted: 7 May 2014 - Published: 20 June 2014

\begin{abstract}
During the dry season the Amazon forest is frequently covered by shallow cumulus clouds fields, referred to here as forest cumulus $(\mathrm{FCu})$. These clouds are shown to be sensitive to land cover and exhibit a high level of spatial organization. In this study we use satellite data to perform a morphological classification and examine the link between $\mathrm{FCu}$ cloud field occurrence and the enhanced vegetation index (EVI), which is commonly used as a measure for forest density and productivity. Although weaker than first-order effects of meteorology, a clear positive linear relation between EVI (i.e., surface properties) and FCu field occurrence is seen over forest land cover, implying a strong coupling between forest surface fluxes and the cloud organization above. Over non-forest land cover the relationship between EVI and $\mathrm{FCu}$ occurrence is nonlinear, showing a reduction of $\mathrm{FCu}$ for high EVI values. We find that forest to non-forest transition zones display a superposition of the two different land cover dependencies.
\end{abstract}

\section{Introduction}

During the Amazon dry season (austral winter months, JuneSeptember), the Intertropical Convergence Zone (ITCZ) moves northward (reaches $\sim 10^{\circ} \mathrm{N}$ in mid-August), while large-scale subsidence associated with the South Atlantic Subtropical High (SASH) dominates the region (Nobre et al., 1998) and relatively stable meteorological conditions prevail. Under these conditions, organized fields of shallow cumulus $\mathrm{Cu}$ clouds form over and near the forest during the daytime hours when surface triggered convection is possible and the humidity near the canopy is high enough. The formation of these clouds has a clear diurnal cycle with a maximum during the afternoon.

A typical satellite image of these cloud fields can be seen in Fig. 1, taken on 1 September 2011, 13:30 LST. The clouds form almost exclusively over land areas; in other words, clouds are absent above the Amazon River and its tributaries. One of the noticeable, although not exclusive, properties of these clouds is their tendency to organize in linear patterns (Fig. 2). They can often be considered analogous to cloud streets (Ramos da Silva et al., 2011), which are typically observed during cold air outbreaks over warmer oceanic waters (Brümmer, 1999). In this work these cloud fields are shown to be very sensitive to changes in the environmental conditions and therefore they can serve as a "laboratory" for studying the conditions in which they form. They are hereafter referred to as forest cumulus (FCu) fields (more details on the $\mathrm{FCu}$ are given in Sect. 2). Daytime FCu cloud fields similar to those seen in Figs. 1 and 2 can be observed in several other locations around the globe, such as central Africa during most of the year or northeast America and Siberia during the boreal summer. The common denominator in all cases is their preferred formation over dense, large-scale forests during stable meteorological conditions, when formation of more developed clouds is suppressed.

Land cover change effects on clouds can be divided by temporal and spatial scales into short- (immediate) or longterm effects, or local to global spatial scales (Pielke $\mathrm{Sr}$ et al., 2011); here we will focus on the short-term ones. The immediate effects of land cover changes are attributed to changes in the surface radiation budget (Betts, 2009). Different land cover types exhibit different albedo, surface 


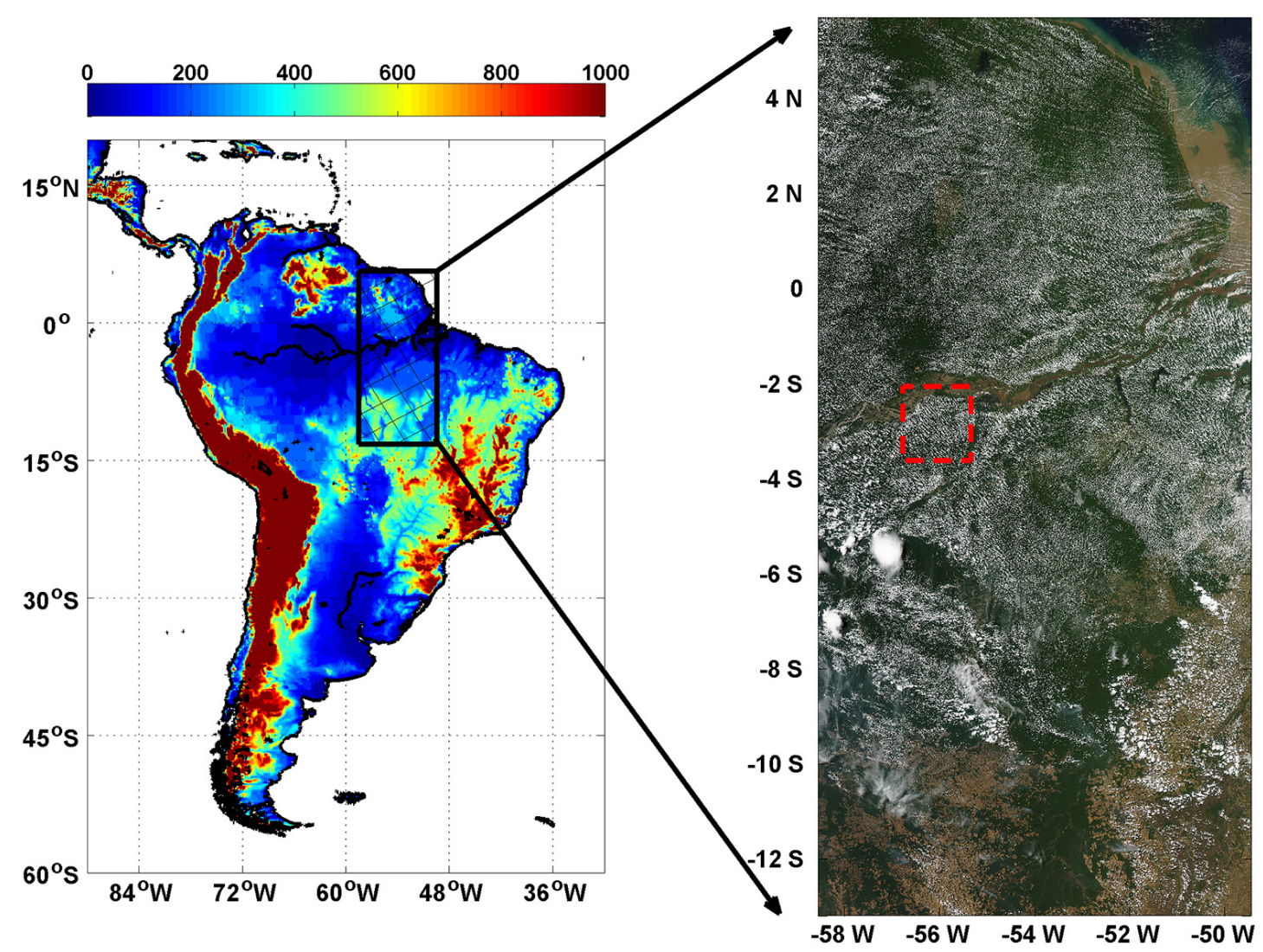

Figure 1. Left: topographic map of South America (note that the color bar is capped at $1000 \mathrm{~m}$ ); study region indicated by cross-hatched box. Map based on ETOPO1 1 arcmin global relief model data set (Amante and Eakins, 2009). Right: typical forest cumulus (FCu) fields over the Amazon Basin study region. GeoTIFF image taken from MODIS Rapid Response USDA Foreign Agricultural Service (FAS) subsets. The dashed red box indicates the area magnified in Fig. 2. Image corresponds to 1 September 2011, 13:30 LST. The Amazon River and its tributaries inhibit all types of cloud formation.

roughness, moisture content, etc. (Bastable et al., 1993). Such changes affect the energy fluxes to the atmosphere, the partition of this energy to sensible and latent heat, and the turbulent transfer of those fluxes to the atmosphere. Eventually, these changes influence the diurnal evolution of the atmospheric boundary layer (Betts, 2000). The latter study showed how vegetation resistance controls the boundary layer depth (with lowest resistances corresponding to the oceanic limit) and the partition between latent and sensible heat fluxes. Hence, the evapotranspiration properties of the land cover vegetation are tightly linked to the dynamics of the boundary layer and the shallow $\mathrm{Cu}$ clouds, which commonly cap the boundary layer.

Deforested areas in the Amazon (either pasture or cropland) usually display higher sensible heat and lower latent heat fluxes in comparison with the forested areas, which in turn can enhance the growth of the boundary layer during the day and favor the formation of larger convective clouds (Fisch et al., 2004). Moreover, surface heterogeneities often result in local mesoscale breezes which can also affect low- level convergence patterns and cloud formation (Rabin et al., 1990; Souza et al., 2000).

Generally there exists a preference for shallow $\mathrm{Cu}$ formation over densely forested rather than deforested areas (located around the southern boundaries of the Amazon Basin; see Fig. 1) (Cutrim et al., 1995). However, most observational studies, including those listed above, have focused exclusively on deforested pockets within forested areas, showing a clear preference for shallow $\mathrm{Cu}$ formation over deforested areas (Cutrim et al., 1995; Chagnon et al., 2004; Wang et al., 2009) and for deep convective cloud formation over the surrounding forested areas (Wang et al., 2009).

These differences in shallow $\mathrm{Cu}$ preference could arise due to emphasis put on mesoscale circulations (driven by land cover transitions) rather than more subtle changes within a specific land cover type. Moreover, studies showing preference for shallow $\mathrm{Cu}$ over deforested land cover are confined mainly to the southwest regions of the Amazon, which are highly deforested and experience very stable meteorological conditions during the dry season. Studies in other regions of the world such as southwestern Australia (Ray et al., 2003) 


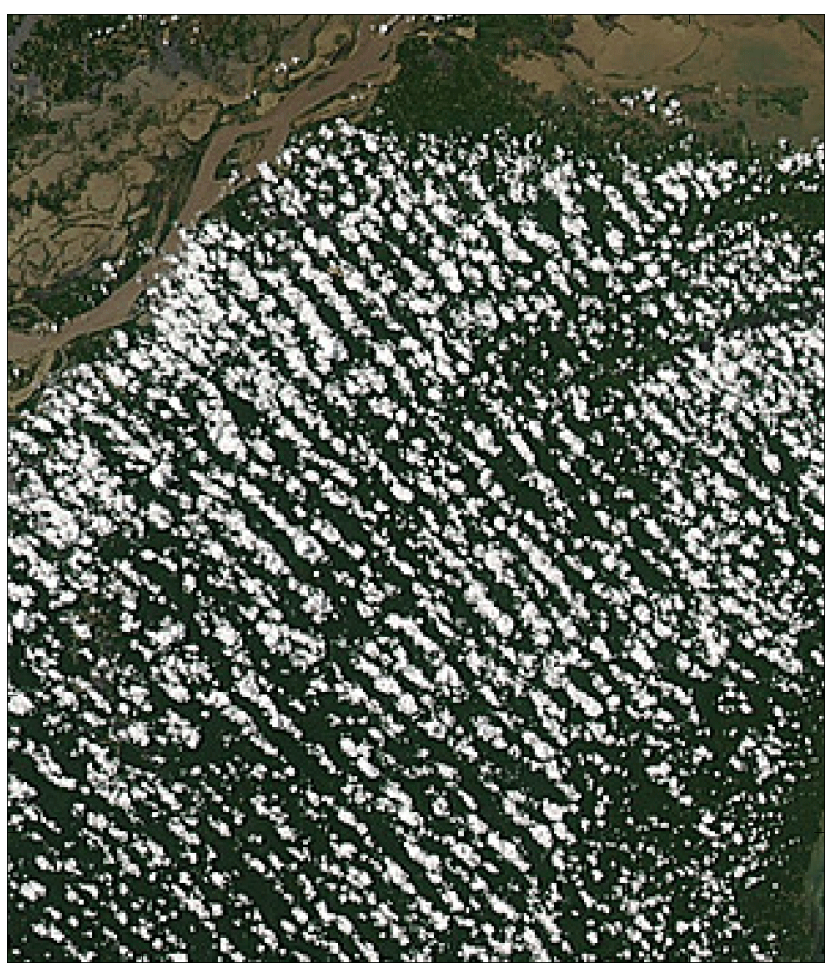

Figure 2. Magnified view of forest cumulus $(\mathrm{FCu})$ cloud fields (subset of Fig. 1). Note the linear patterns in which the $\mathrm{FCu}$ organize. The scale of the box is $150 \mathrm{~km} \times 175 \mathrm{~km}$.

and Costa Rica (Nair et al., 2003) show a preference for shallow cumulus formation over native vegetation and forested areas rather than adjacent deforested areas.

Much of the Amazon deforestation is a result of massive biomass burning events which occur during the dry season (Koren et al., 2004). Biomass burning emits high concentrations of absorbing aerosols into the atmosphere, which can interact with radiation (i.e., scatter and absorb shortwave radiation) and affect the temperature profile and therefore static stability, or serve as cloud condensation nuclei $(\mathrm{CCN})$ and affect the microphysical processes and evolution of clouds and precipitation (Koren et al., 2008). Hence, it is essential to address aerosol effects on clouds in the region as well.

The goal of this work is to evaluate the morphological characteristics of the Amazon FCu fields, and to use a statistical approach to study the effects of land cover change on the $\mathrm{FCu}$ fields over the Amazon region. Specifically we use the EVI (enhanced vegetation index) as a measure of the well-being of the forest. It has been shown that this index correlates well with forest productivity and canopy density (Glenn et al., 2008; Sjöström et al., 2011), and can be a good predictor for evapotranspiration and moisture fluxes to the lower atmosphere (Mu et al., 2007; Juárez et al., 2008), which in turn drive the formation of dry season Amazonian clouds (Betts and Silva Dias, 2010).

\section{Methods}

We combine satellite data in the visible for cloud morphology and aerosol optical depth (AOD) analyses, land cover type and vegetation indices for surface characterization, and analysis data for specification of the meteorological conditions. True color data at $0.5 \mathrm{~km}$ resolution, AOD data at $1^{\circ}$ resolution, and land surface properties derived from the MODerate-resolution Imaging Spectroradiometer (MODIS) onboard the Aqua satellite are used (Salomonson et al., 1989; Friedl et al., 2010; Running et al., 1994; Remer et al., 2005). The Aqua overpass is at 13:30 LST, at the time when energy fluxes from the surface are maximum (Fisch et al., 1996) and the $\mathrm{FCu}$ fields over the Amazon are already established. The study region of interest is seen in Fig. 1, and spans from $58.54^{\circ} \mathrm{W}, 5.69^{\circ} \mathrm{N}$ (northwest corner) to $49.45^{\circ} \mathrm{W}, 13.19^{\circ} \mathrm{S}$ (southeast corner), an area of $2100 \mathrm{~km} \times 950 \mathrm{~km}$. The topography of the study region is low, and devoid of large gradients except for some patches in the northern part and a gradual rise to higher topography in the southern part. Analyses show that the FCu fields had no clear correlation with topography. Therefore, we exclude analyses of topography effects in this work. Data were collected for the dry season months, JulyAugust-September (J-A-S), during the years 2008-2011.

Our analyses of the $\mathrm{FCu}$ cloud field properties were focused on the statistical properties of the cloud distribution within the field. Measures such as cloud area, average distances between cloud centers, and level of organization were tested to optimize the classification. Unlike the case of a single cloud analysis when the sensitivity to the exact cloudy pixel is crucial and one needs to either avoid cloud contamination of the cloud-free atmosphere (Martins et al., 2002) or, in the case of cloud retrievals, make sure that the cloud mask is free of non-cloudy pixels (Ackerman et al., 1998), our spatial-statistical measures (summarized in Fig. 3) exhibit less sensitivity to the exact method by which clouds are masked in the field.

The first stage of processing is the construction of a basic cloud mask, achieved by applying a threshold $(>0.58)$ to the reflectance of the RGB channels (bands 1,3 , and 4, respectively). Unlike clouds, most bright pixels that are not clouds (e.g., bright roads or sand patches) are not white (e.g., have spectral dependence in the visible spectrum); therefore another threshold $(<0.08)$ is applied to the absolute differences in the reflectance between the red and blue. The morphological characteristics of the cloud field were calculated for a moving window of $51 \times 51$ pixels $(25.5 \mathrm{~km} \times 25.5 \mathrm{~km})$. Five basic characteristics were shown to contain most of the information: cloud fraction, mean and standard deviation of distances between cloud centroids, and mean and standard deviation of cloud areas.

Based on the above criteria we classified the cloud fields into three classes: $\mathrm{FCu}$, deeper convective clouds, and sparse to no clouds (see Table 1). The classification was tuned and validated visually using data from hundreds of boxes of cloud 
a)

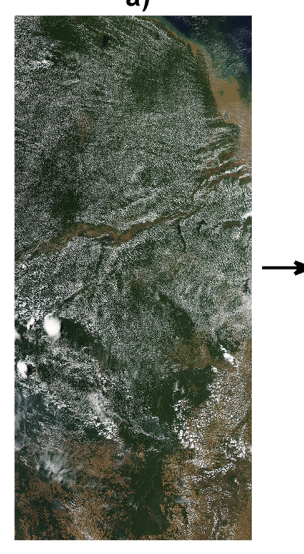

b)

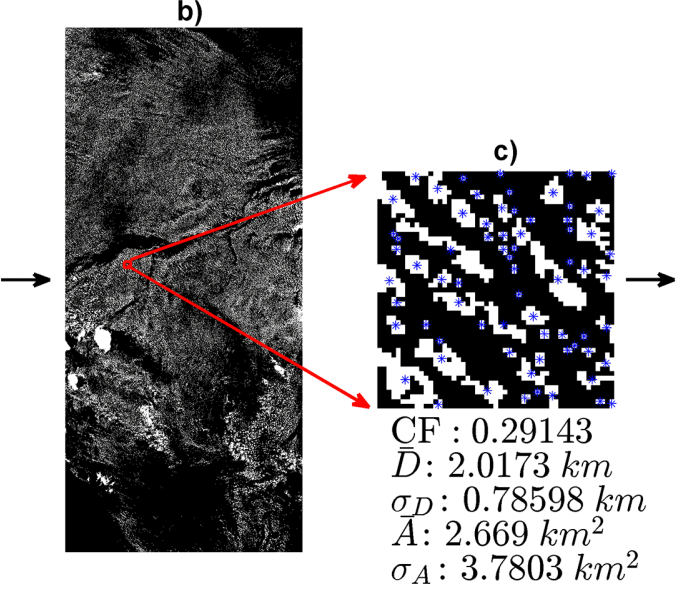

d)

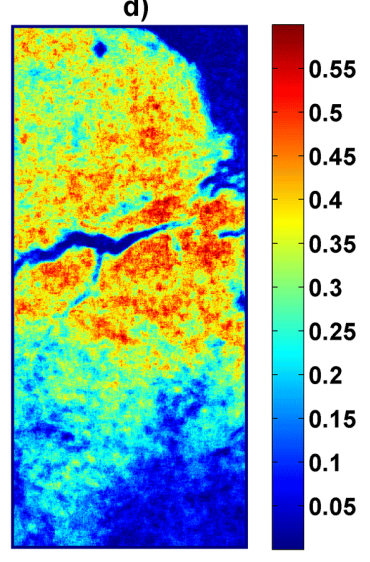

Figure 3. Summary of FCu field detection algorithm for 2011. (a) Corresponding true color geoTIFF image from Fig. 1. (b) Cloud mask of true color image; the red box represents a $25.5 \mathrm{~km} \times 25.5 \mathrm{~km}$ moving window. (c) Close-up of the moving window. Blue asterisks indicate the centroids of individual clouds. Selected statistics of windows are listed below the panel. In this case the cloud field within the window passed the FCu field thresholds listed in Table 1. (d) Final product of algorithm, probability (0-1) of observing FCu field (pFCu) during J-A-S 2011.

Table 1. Moving window thresholds for forest $\mathrm{Cu}(\mathrm{FCu})$, deep convective $\mathrm{Cu}$, and sparse to no $\mathrm{Cu}$ cloud fields. Thresholds include cloud fraction $(\mathrm{CF})$, mean cloud area $(\bar{A})$, standard deviation of cloud areas $\left(\sigma_{A}\right)$, mean distance between cloud centroids $(\bar{D})$, and standard deviation of distances $\left(\sigma_{D}\right)$. Missing data represent thresholds that are not relevant to the analysis.

\begin{tabular}{lrrrrrrrrrr}
\hline Parameter $\rightarrow$ & \multicolumn{2}{c}{ CF $[\%]$} & \multicolumn{2}{c}{$\bar{A}\left[\mathrm{~km}^{2}\right]$} & \multicolumn{2}{c}{$\sigma_{A}\left[\mathrm{~km}^{2}\right]$} & \multicolumn{2}{c}{$\bar{D}[\mathrm{~km}]$} & \multicolumn{2}{c}{$\sigma_{D}[\mathrm{~km}]$} \\
Field type $\downarrow$ & Low & High & Low & High & Low & High & Low & High & Low & High \\
\hline Forest cumulus & 0.15 & 0.4 & 1.5 & 8 & 1.5 & 12.5 & 1.8 & 3.2 & 0.6 & 1.3 \\
Sparse & 0 & 0.1 & 0 & 3 & 0 & 3 & - & - & - & - \\
Deep convective & 0.6 & 1 & 50 & - & - & - & - & - & - & - \\
\hline
\end{tabular}

fields (see Fig. 3c). The boxes were used to calculate the mean statistics of the $\mathrm{FCu}$ clouds fields. The typical values for the morphological characteristics of the three defined fields types are shown in Table 2. The narrow distributions and interannual consistency of these key cloud properties allowed for a robust detection of the fields.

After performing the analysis above for all days during J-A-S for a specific year (a total of 75-80 overpasses), the probability for an $\mathrm{FCu}$ field to exist (hereafter named $\mathrm{pFCu}$ ) was calculated for each pixel (see Fig. 3d). Similar methodologies have been used in other studies of shallow cumulus clouds (Ray et al., 2003; Cutrim et al., 1995). It is important to note that the classification results were shown to be robust and not sensitive to small variations in the selected thresholds.

Yearly classification of different land cover types was done using the MODIS collection 5 MCD12Q1 product (Friedl et al., 2010). The product includes five types of land cover classifications, out of which the 14-class University of Maryland (UMD) classification was chosen (Hansen et al., 2000). For the purposes of this study, we divided the UMD land cover classification into three types: (i) forest, classes 1 through 5 (i.e., all forest types including mixed); (ii) non-forest, classes 6 through 10 (woodlands, grasses, shrublands), 12 (croplands), 13 (urban), and 16 (barren); and (iii) water, class 17. An example of such a classification map for 2011 is seen in Fig. 4a.

Spectral definitions for MODIS vegetation indices: NDVI (normalized difference vegetation index) and EVI, and their validations over numerous sites can be found in previous papers (Huete et al., 2002; Mu et al., 2007). Both vegetation indices can be used to assess the surface energy budget components (latent heat, Bowen ratio) and plant physiology components such as evapotranspiration, leaf area index, fractional vegetation cover, canopy architecture, and more (Glenn et al., 2008). Since NDVI tends to saturate in areas of high biomass (Huete et al., 2002), and is more sensitive to atmospheric aerosol contamination (Xiao et al., 2003), EVI is preferred in our study.

Furthermore, studies have shown EVI to be better correlated with evapotranspiration than NDVI, with linear correlation coefficients $\left(r^{2}\right)$ usually ranging between 0.7 and 0.9 (Glenn et al., 2010; Nagler et al., 2005). Henceforth we shall use EVI as a general measure of vegetation density and 
Table 2. Average statistics for the cloud fields (and their spatial parameters) as defined in Table 1, years 2008-2011. Missing data represent irrelevant statistics (for example, distance between clouds is meaningless for sparse and deep convective fields since we commonly observe only one cloud within the $25 \mathrm{~km}$ moving window).

\begin{tabular}{|c|c|c|c|c|c|c|}
\hline $\begin{array}{l}\text { Parameter } \rightarrow \\
\text { Field type } \downarrow\end{array}$ & Year & $\mathrm{CF}[\%]$ & $\bar{A}\left[\mathrm{~km}^{2}\right]$ & $\sigma_{A}\left[\mathrm{~km}^{2}\right]$ & $\bar{D}[\mathrm{~km}]$ & $\sigma_{D}[\mathrm{~km}]$ \\
\hline \multirow{4}{*}{ Forest cumulus $(\mathrm{FCu})$} & 2008 & $0.23 \pm 0.02$ & $2.93 \pm 0.37$ & $5.79 \pm 1.08$ & $2.21 \pm 0.12$ & $0.91 \pm 0.07$ \\
\hline & 2009 & $0.23 \pm 0.02$ & $3.00 \pm 0.31$ & $5.64 \pm 0.95$ & $2.26 \pm 0.10$ & $0.90 \pm 0.06$ \\
\hline & 2010 & $0.24 \pm 0.02$ & $3.03 \pm 0.41$ & $5.80 \pm 1.13$ & $2.25 \pm 0.13$ & $0.88 \pm 0.07$ \\
\hline & 2011 & $0.24 \pm 0.02$ & $3.13 \pm 0.37$ & $5.65 \pm 1.00$ & $2.31 \pm 0.13$ & $0.87 \pm 0.07$ \\
\hline \multirow{4}{*}{ Sparse } & 2008 & $0.03 \pm 0.02$ & $1.31 \pm 0.43$ & $1.33 \pm 0.43$ & - & - \\
\hline & 2009 & $0.04 \pm 0.01$ & $1.24 \pm 0.38$ & $1.24 \pm 0.42$ & - & - \\
\hline & 2010 & $0.03 \pm 0.02$ & $1.55 \pm 0.62$ & $1.54 \pm 0.63$ & - & - \\
\hline & 2011 & $0.03 \pm 0.02$ & $1.39 \pm 0.47$ & $1.33 \pm 0.50$ & - & - \\
\hline \multirow{4}{*}{ Deep convective } & 2008 & $0.83 \pm 0.06$ & $144.0 \pm 58.2$ & - & - & - \\
\hline & 2009 & $0.82 \pm 0.06$ & $139.7 \pm 56.7$ & - & - & - \\
\hline & 2010 & $0.83 \pm 0.06$ & $143.5 \pm 56.4$ & - & - & - \\
\hline & 2011 & $0.83 \pm 0.06$ & $143.9 \pm 59.8$ & - & - & - \\
\hline
\end{tabular}
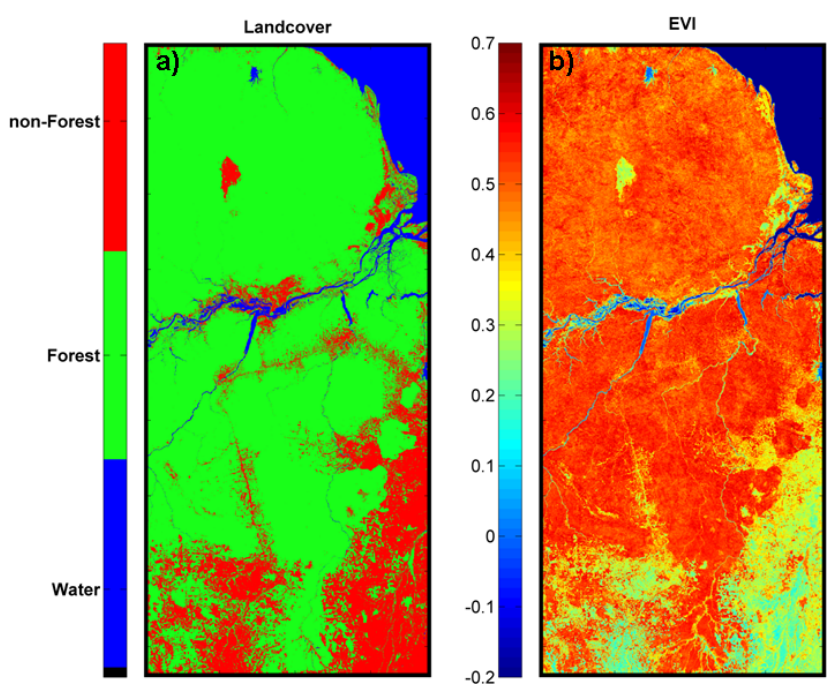

Figure 4. Land cover classification map (a) and mean J-A-S EVI (b) for the year 2011 .

productivity over the forest and non-forest land covers. The mean J-A-S EVI for 2011 is shown in Fig. 4b. The domain shows high EVI values over forest land cover in comparison with non-forest land cover, with the latter also showing much larger EVI variance. Very similar EVI maps are seen for years 2008-2010.

Focusing on the southern half of the domain, Fig. 3d clearly shows reduction in the probability for $\mathrm{FCu}$ fields. The same pattern exists for the year 2008-2010. Using NOAANCEP Global Data Assimilation System (GDAS) analysis data (Saha et al., 2006; Parrish and Derber, 1992), we examined the spatial patterns of various meteorological parameters (J-A-S averages). The two parameters that were found to best reflect the spatial variance of the $\mathrm{FCu}$ fields are the geopotential height (HGT) at $700 \mathrm{hPa}$ (see Fig. 5a) and the relative humidity (RH) at $850 \mathrm{hPa}$ (see Fig. 5b). These parameters can also be seen as physically tightly linked to $\mathrm{FCu}$ formation. High geopotential height at $700 \mathrm{hPa}$ (pressure levels of 850-500 hPa give similar results) indicates upper level subsidence, adiabatic warming and drying, and is associated with the SASH (Figueroa and Nobre, 1990). Relative humidity at $850 \mathrm{hPa}$ corresponds to the mean cloud base height (based on ceilometer measurements), and is essential to cumulus formation.

\section{Results}

\subsection{Forest cumulus $(\mathrm{FCu})$ dependence on meteorology}

The meteorological context of the FCu probability for 2011 is shown in Fig. 5c and d. The north-south pFCu differences over the land are best captured by the HGT at $700 \mathrm{hPa}$ field. The value of HGT $=3157 \mathrm{~m}$ (indicated by the dashed line in Fig. 5a and solid line in Fig. 5c) was chosen as the boundary between the northern part of the Amazon region (NA in Fig. 5a, c) that shows little meteorological variance and the southern part of the Amazon region (SA in Fig. 5a, c) that shows high coupling between $\mathrm{pFCu}$ and meteorology. Hence, in order to minimize meteorological influence, only the northern region (NA) is used to test large-scale vegetation index effects on $\mathrm{FCu}$ fields.

Patterns of RH at $850 \mathrm{hPa}$ may affect some of the features seen in Fig. 3d as well. The southeast-to-northwest positive gradient in the southern Amazon (SA) $\mathrm{pFCu}$ seems to correspond to an equivalent RH gradient seen in Fig. 5b. Additionally, from the dependence of $\mathrm{pFCu}$ on $\mathrm{RH}$ in Fig. $5 \mathrm{~d}$, we can see that areas with high $\mathrm{RH}(\mathrm{RH}>80 \%$, indicated by the 

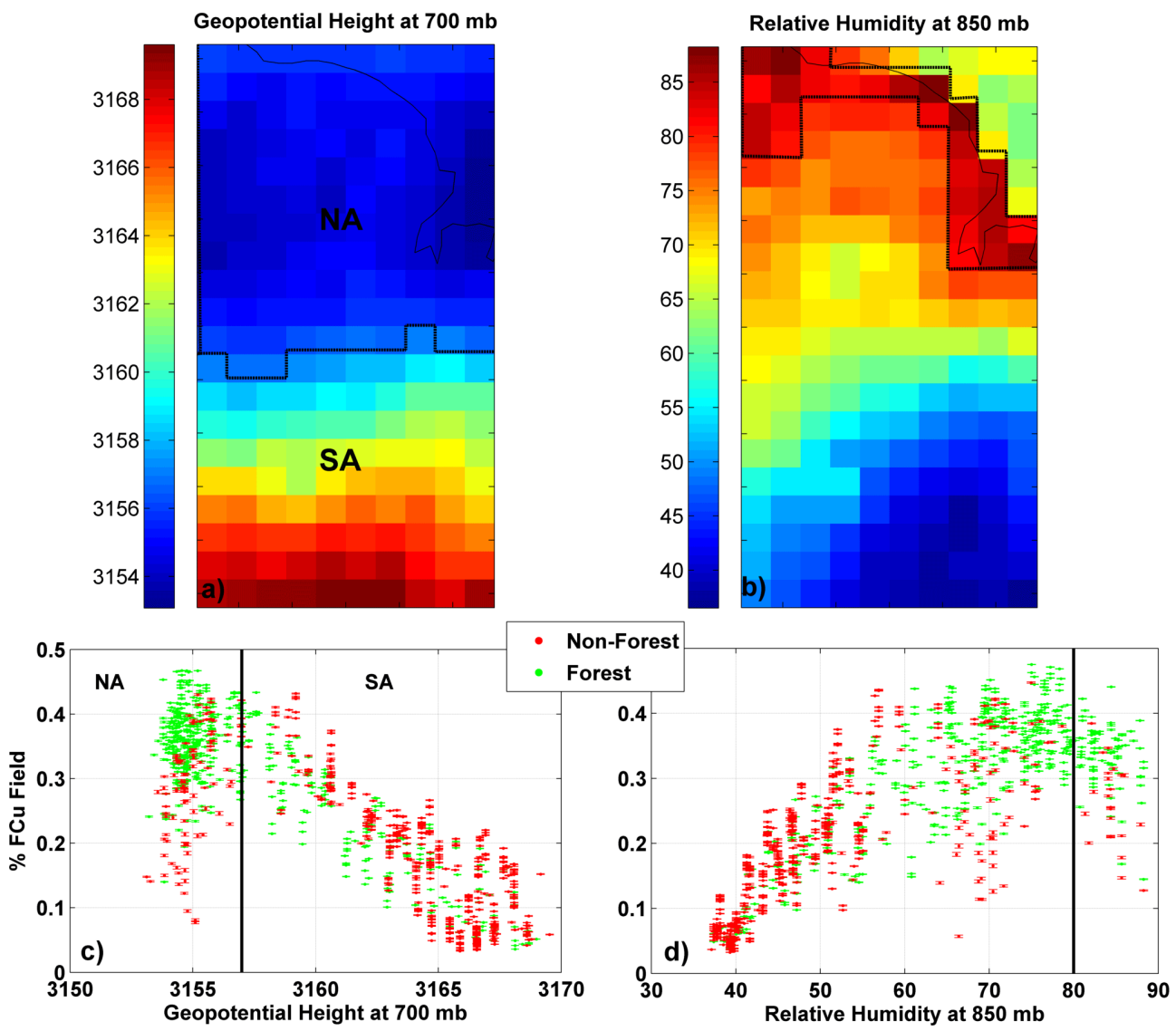

Figure 5. Meteorological setting (based on GDAS analysis data) in the Amazon during J-A-S and the effects on pFCu over forest and non-forest land covers. (a) geopotential height (HGT) [m] at $700 \mathrm{hPa}$ pressure level; the dashed line represents the border between NA and SA regions. (b) Relative humidity $(\mathrm{RH})[\%]$ at $850 \mathrm{hPa}$; high- $\mathrm{RH}$ areas enclosed within the dashed line are excluded from further analyses. (c) Chance of observing FCu field as a function of HGT at $700 \mathrm{hPa}$. Data are sorted into 500 bins, with 11484 and 2808 counts per bin for forest and non-forest, respectively. The black line represents HGT separation between NA and SA regions. (d) Same as (c), but for RH at $850 \mathrm{hPa}$. Data above $\mathrm{RH}=80 \%$ (black line in panel) are excluded from analyses in this work.

dashed line in Fig. 5b) are less favorable for $\mathrm{FCu}$ formation. The high RH areas are mainly coastal regions, and the reduction in $\mathrm{pFCu}$ there is probably due to increased cloud activity (i.e., the cloud fraction $(\mathrm{CF}) /$ mean area $\left(\sigma_{A}\right)$ in coastal areas is frequently above the upper thresholds in Table 1) as a result of mesoscale coastal breezes observed in many previous works, e.g., Heiblum et al. (2011) and Malda et al. (2007).

As seen in Fig. $5 \mathrm{c}$ and d, the large-scale pFCu dependence on the two meteorological parameters is similar for both forest and non-forest land cover types.

Meteorological dependencies of EVI were checked as well for both forest and non-forest land covers. For the forest land cover (as can be seen in Fig. 4), EVI is relatively constant for all meteorology, indicating that EVI reflects an inherent forest property. However, the non-forest land cover EVI is tightly linked to the meteorology, and therefore any correlations between EVI and $\mathrm{pFCu}$ over non-forest may actually correspond to meteorological variance.

\subsection{Interannual comparison of cloud fields and AOD}

The average AOD together with the cloud field detection algorithm results for the years 2008-2011 are summarized in Fig. 6. Previously discussed cloud features such as FCu field preference over the northern part of region, and preference for deep convective clouds in high RH areas (i.e., coastal and northwestern areas), are seen for all four years. The relatively high chance for deep convective clouds in the northwest part of the study region may be due to variable terrain and complex topography in that region as well (see Fig. 1). Water bodies such as the Amazon River, Atlantic Ocean, and lakes clearly inhibit all types of cloud formation. The southern part of the region experiences little or no clouds at all, due to the dry and stable meteorology in that area. The year 2009 shows the highest occurrence of $\mathrm{FCu}$ formation throughout the domain. Meteorological conditions during that year show a more homogeneous pattern of $\mathrm{RH}$ at $850 \mathrm{hPa}$ compared to other years (i.e., higher RH at the southern part (SA) and 

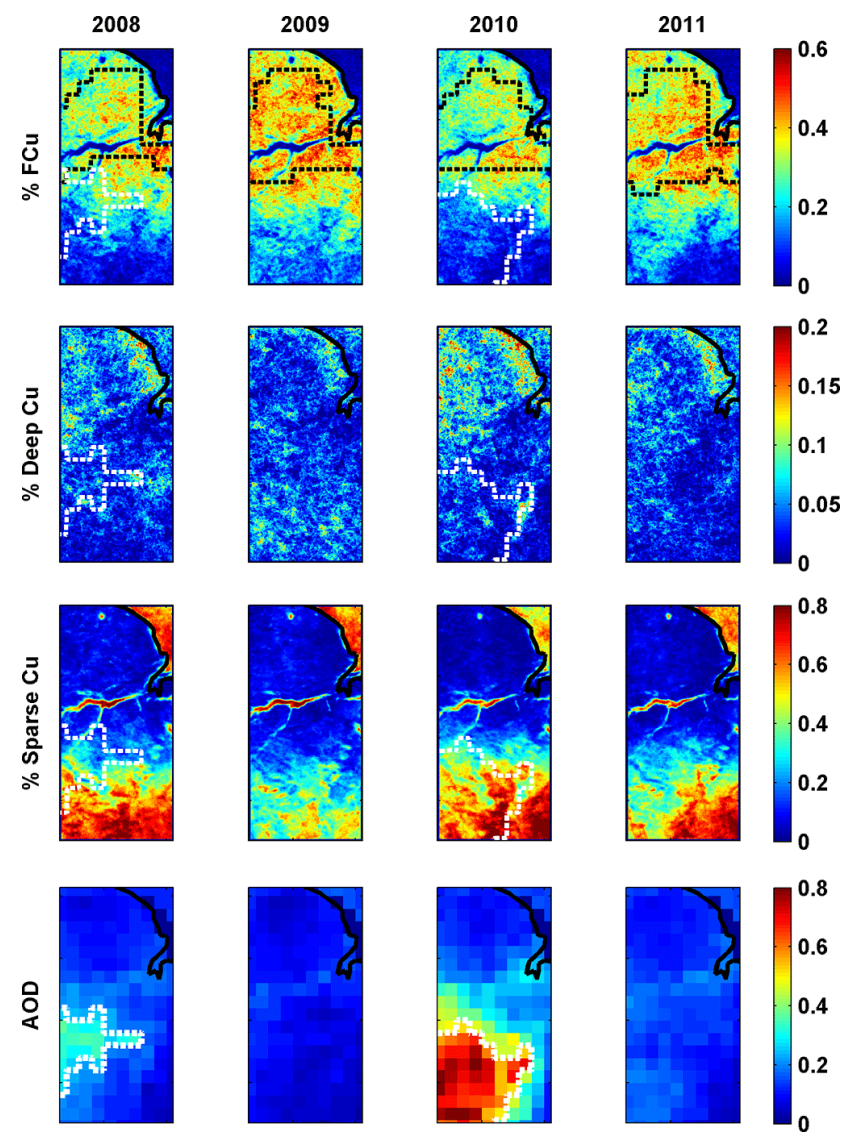

Figure 6. Cloud field statistics and AOD during J-A-S for 2008 (left panels) to 2011 (right panels). Panels include (from top to bottom) chance for FCu field, chance for deep convective cumulus field, chance for sparse to no cumulus field, and mean AOD taken from the Giovanni online data system. White dashed contours in 2008 (2010) panels indicate the region of AOD > 0.25 (0.5). Black dashed contours in upper panels represent areas with minimized meteorological variance (see Sect. 3.1), for each year, used in Sect. 3.3 for EVI vs. pFCu analyses. High-AOD pixels along the mouth of the Amazon River were discarded as they correspond to a MODIS AOD algorithm artifact in that area due to the sediment-laden waters there.

lower RH in the northern part (NA)), which could be responsible for the increase in $\mathrm{pFCu}$.

A striking difference in AOD between the years can be seen, with average values reaching above $0.4(0.8)$ in the southwest part of the region during 2008 (2010) but limited to 0.25 during 2009 and 2011. Moreover, the spatial variance of AOD is much smaller during 2009 and 2011, and is unlikely to be a major factor in $\mathrm{pFCu}$ variability. The extremely high AOD during 2010 can be explained by both the extreme drought (Lewis et al., 2011) and frequent fires (Ten Hoeve et al., 2012) (i.e., abundance of biomass burning aerosol) in the Amazon Basin that year. However, it should be noted that the drought's effect on our study region was minimal compared to the rest of the basin.
Since areas of high AOD (white contours in Fig. 6) do not overlap with areas of relatively constant meteorological conditions that are favorable for $\mathrm{FCu}$ formation (black contours in Fig. 6), and due to ambiguous signals (both temporal and spatial) of aerosol effects on clouds for the whole domain, we assume these effects (described in Sect. 1) are unlikely to be a strong forcing for the spatial distribution of $\mathrm{pFCu}$.

\subsection{Enhanced vegetation index (EVI) effect on forest cumulus $(\mathrm{FCu})$ fields}

To minimize influences of meteorology (and potentially also aerosol) on the data, we limit the current analysis of EVI effects on $\mathrm{FCu}$ fields to the NA region excluding $\mathrm{RH}>80 \%$ areas during 2011 (area enclosed by dashed black contour, Fig. 6), taken as a representative example. The J-A-S pFCu data (Fig. 3d) were sorted as a function of the mean J-A-S EVI data (Fig. 4b) for forest (blue dots) and non-forest (magenta dots) land covers separately (see Fig. 7a). Bin statistics are included in the figure legend. For the forest land cover, we see a positive dependence of $\mathrm{pFCu}$ on EVI. This dependence is especially strong for the lower EVI values. The increase in $\mathrm{pFCu}$ then saturates at a moderate value of about $\mathrm{EVI}=0.54$. For the non-forest land cover, the dependence of $\mathrm{pFCu}$ on EVI is somewhat different. For low EVI values (EVI < 0.48), there is a strong positive dependence (similar to that seen in forest land cover), but for higher values of EVI $>0.48$ there is a clear decrease of $\mathrm{pFCu}$ with EVI. It is important to note that for all EVI values, there is a higher chance of observing an $\mathrm{FCu}$ field above forest land cover than non-forest land cover.

Until now, we have focused on limiting the effects of meteorological and aerosol variance on $\mathrm{pFCu}$, but have yet to consider the effects of mesoscale circulations that may form at the boundaries and transition areas between land cover types. Since these circulations are local, their intensity can be represented by the distance from the land cover boundaries. As seen in Fig. $7 \mathrm{~b}$ for the NA region, $\mathrm{pFCu}$ over forest land cover is lowest close to the boundaries with other land cover types, then increases sharply with large variance at short distances $(<5 \mathrm{~km})$, and is relatively constant at distances larger than $\sim 10 \mathrm{~km}$. The variance seen for distances higher than $80 \mathrm{~km}$ may be due to local topography and forest changes. To try to eliminate the mesoscale effects from the EVI analysis, we divided the data into two subsets: (i) forest data within $10 \mathrm{~km}$ of other land cover types (Fig. 7c), which we assume includes the bulk of mesoscale circulation effects, and (ii) forest data further than $10 \mathrm{~km}$ away from other land cover types (Fig. 7d), which we consider to be free of mesoscale circulation effects. There was no point in doing the same exercise for non-forest land cover since more than $95 \%$ of that data are closer than $10 \mathrm{~km}$ to other land cover types.

Figures $7 \mathrm{c}$ and $\mathrm{d}$ illustrate how the $\mathrm{pFCu}$ dependence on EVI shifts as we penetrate deeper into the forested areas. In Fig. 7c, forest land cover data were divided into $0-1 \mathrm{~km}$, 

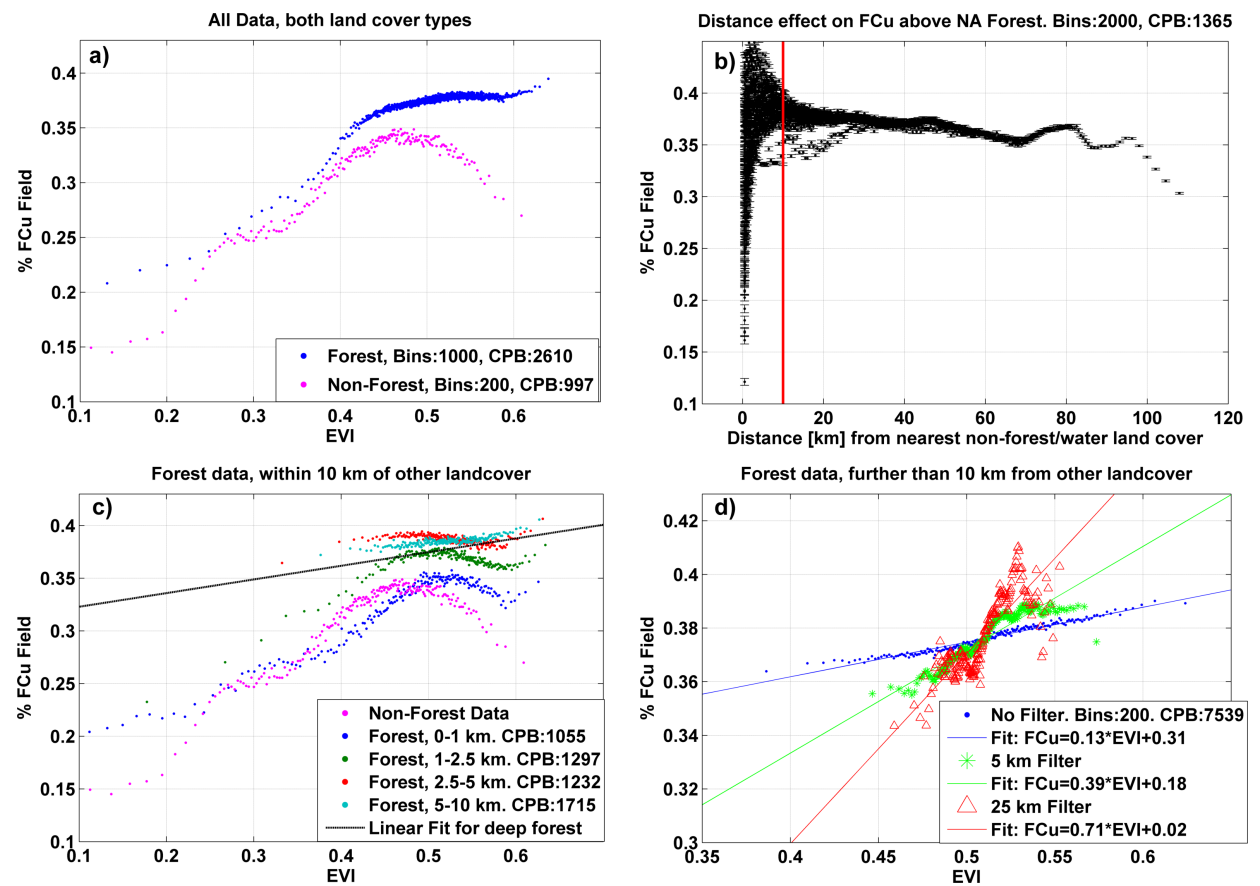

Figure 7. pFCu field as a function of EVI in the NA region (with $\mathrm{RH}<80 \%$ ) during J-A-S, 2011. (a) All data above forest and non-forest land cover types. Counts per bin (CPB) included in panel legend. (b) pFCu field over forest land cover as a function of distance (km) from nearest non-forest/water land cover pixel. Data correspond to NA region (with $\mathrm{RH}<80 \%$ ). (c) Same as (a) but with forest land cover data constrained to within $10 \mathrm{~km}$ of other land cover types and sorted into 200 bins. The forest data were divided into four distances from other land cover subsets (see legend) to illustrate the transition from a non-forest-like dependence to a deep-forest-like dependence. The black dashed line is the linear fit for deep forest EVI dependence seen in panel (d). (d) Same as (a) but only for forest land cover data further than $10 \mathrm{~km}$ from other land cover types. Panel includes raw EVI data (blue) and EVI smoothed with a $5 \mathrm{~km}$ (red) or $25 \mathrm{~km}$ (green) disk filter. Linear fits for all cases added in panel legend.

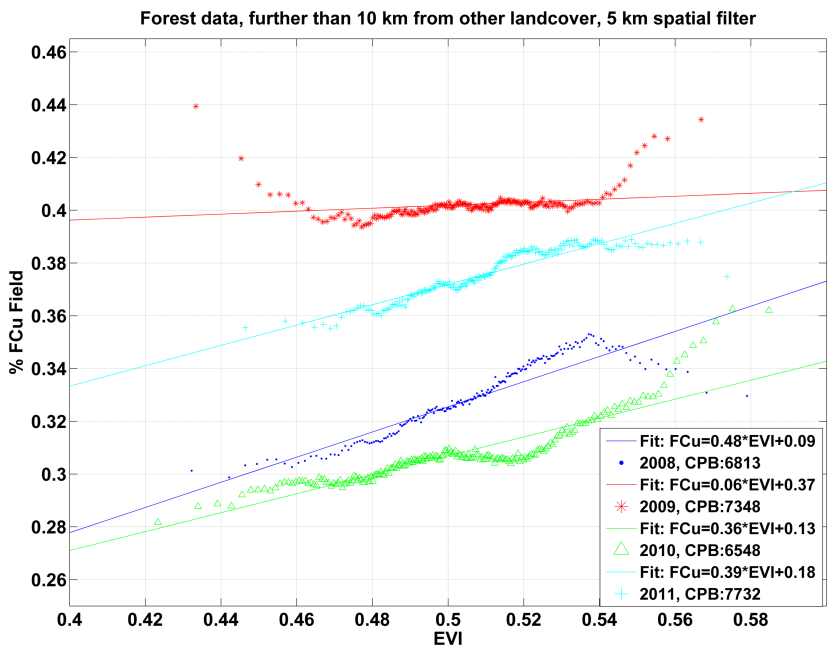

Figure 8. Four year (2008-2011) comparison of $\mathrm{pFCu}$ field as a function of EVI, for forest land cover data further than $10 \mathrm{~km}$ from other land cover types, and sorted into 200 bins. A $5 \mathrm{~km}$ spatial disk filter was applied to the EVI data. Counts per bin (CPB) and linear fits for all years added in figure legend.
$1-2.5 \mathrm{~km}, 2.5-5 \mathrm{~km}$, and $5-10 \mathrm{~km}$ distance intervals from any other land cover. The non-forest $\mathrm{pFCu}$ dependence on EVI from Fig. 7a is added for reference. A gradual transition from a non-forest-like dependence on EVI to a deep-forest-like dependence on EVI (i.e., positive linear, black dashed line in Fig. 7c) is seen. Hence, we can assume that in transition zones between forest land cover and water/non-forest land covers, a superposition of deep forest and non-forest dependencies on EVI takes place. Generally, for a given EVI value the further the distance from water/non-forest land covers, the higher the chance of observing FCu fields.

For deep forest data further than $10 \mathrm{~km}$ away from other land cover types (blue dots, Fig. 7d) we can see a positive linear dependence of $\mathrm{pFCu}$ on EVI. We applied a linear fit to the data ( $R^{2}=0.95$; fit details added in figure legend) and obtained a slope of $\frac{\partial(\mathrm{pFCu})}{\partial(\mathrm{EVI})}=0.13$. Clearly, the well-being and productivity of the deep forest promotes the formation of FCu fields. To test the robustness of the linear trend above (Fig. 7d, blue line), we applied two low-pass disk-shaped filters to the EVI data, one with a radius of $5 \mathrm{~km}$ (green stars and line, Fig. 7d) and the other with a radius of $25 \mathrm{~km}$ (red triangles and line, Fig. 7d). Our assumption is that using "smoothed" EVI data, being less sensitive to local noise, 
reveals the more robust larger-scale effects of EVI on $\mathrm{pFCu}$. The results of this analysis show that the positive linear trend seen for the deep forest is indeed robust, with stronger dependencies as filter size increases. The slope of $\mathrm{pFCu}$ vs. EVI increases to 0.39 for the $5 \mathrm{~km}$ filter and 0.71 for the $25 \mathrm{~km}$ filter, an increase of 200 and $450 \%$, respectively. For larger filters with radius $>30 \mathrm{~km}$, the main signal decays because of significant loss of EVI spatial information.

The same process done for 2011 above was repeated for the years 2008-2010. For each year, we took the area with minimum meteorological effect on $\mathrm{pFCu}$ (indicated by black dashed contours in Fig. 6), using the methodology described in Sect. 3.1. Areas of high AOD were partially avoided this way as well, although we cannot rule out influence of aerosols on the results for years 2008 and 2010 especially. Only deep forest data were considered. The results are summarized in Table 3 . The dependence of $\mathrm{pFCu}$ on spatially filtered EVI (only $5 \mathrm{~km}$ filter) for 2008-2011 is shown in Fig. 8.

For all years, an increase in pFCu with EVI is seen, yielding positive slopes for all years and spatial filter sizes (Table 3). The minor reductions in pFCu with EVI, seen in Fig. 8 for very high EVI $(>0.55,2008)$ or low $\operatorname{EVI}(<0.46,2009)$, are probably due to local effects and sparse statistics at those EVI ranges. Consistent with 2011, the larger the spatial filter size, the larger the linear fit slope, showing an average increase of more than $200 \%$ for the $5 \mathrm{~km}$ filter and $400 \%$ for the $25 \mathrm{~km}$ filter (Table 3). At the same time, the data become noisier with increasing filter size, reducing the correlation coefficient values from $\sim 0.9$ without a filter to $\sim 0.6$ for the $25 \mathrm{~km}$ filter. Although consistent with the other years, 2009 shows a much weaker pFCu dependence on EVI. This may be due to the fact that the environmental conditions during that year were especially favorable for $\mathrm{FCu}$ formation throughout the domain (see Fig. 6), reducing the secondorder EVI effect on the clouds.

\section{Discussion and conclusions}

In this work we examine the link between the Amazon forest and the clouds that form above it as part of the effort towards understanding how anthropogenic forest dilution may affect clouds. By defining forest cumulus $(\mathrm{FCu})$ clouds fields, we have created a simple metric that is clearly tightly coupled and highly sensitive to surface changes in the Amazon region. Although chosen subjectively, we note that results of this work are insensitive to changes in the upper and lower thresholds. We tested several sets of threshold ranges, and even though the absolute values of $\mathrm{pFCu}$ do change, the trends obtained in Sect. 3.3 are the same.

A significant part of the analysis concentrated on separating the effects of meteorology and biomass burning from the more subtle effect of land cover EVI. Not surprisingly, the meteorological conditions are the main factor that sets the stage for $\mathrm{FCu}$ formation. Although the entire study region
Table 3. Linear fit statistics for $\mathrm{pFCu}$ vs. EVI dependencies using no filter and 5 and $25 \mathrm{~km}$ spatial disk filters on the EVI data, for years 2008-2011. Statistics include linear fit slope $(a)$, point of intersection with $y$ axis $(b)$, and the $R^{2}$ coefficient.

\begin{tabular}{lrrrr}
\hline $\begin{array}{l}\text { Parameter } \rightarrow \\
\text { Filter size }(\mathrm{km}) \downarrow\end{array}$ & Year & $a$ & $b$ & $R^{2}$ \\
\hline \multirow{3}{*}{ None } & 2008 & 0.23 & 0.21 & 0.93 \\
& 2009 & 0.03 & 0.38 & 0.33 \\
& 2010 & 0.16 & 0.22 & 0.94 \\
& 2011 & 0.13 & 0.31 & 0.95 \\
\hline \multirow{3}{*}{$5 \mathrm{~km}$} & 2008 & 0.47 & 0.08 & 0.84 \\
& 2009 & 0.05 & 0.37 & 0.05 \\
& 2010 & 0.35 & 0.12 & 0.81 \\
& 2011 & 0.39 & 0.18 & 0.87 \\
\hline \multirow{3}{*}{$5 \mathrm{~km}$} & 2008 & 0.74 & -0.04 & 0.64 \\
& 2009 & 0.22 & 0.28 & 0.14 \\
& 2010 & 0.75 & -0.02 & 0.55 \\
& 2011 & 0.71 & 0.02 & 0.74 \\
\hline
\end{tabular}

experiences stable conditions during the dry season, weak meteorological gradients control where $\mathrm{FCu}$ fields can form. The southern Amazon (SA) subset is usually too dry and stable to enable $\mathrm{FCu}$ formation, above forest and non-forest land cover alike. In contrast, the northwestern part and coastal areas of the northern Amazon (NA) subset experience relatively unstable conditions which are realized by the increased presence of deep convective clouds and reduction in $\mathrm{pFCu}$. Regarding the link between surface $\mathrm{EVI}$ and $\mathrm{pFCu}$, five main conclusions can be drawn:

1. FCu fields form exclusively over land areas in the Amazon region, preferably over forest land cover.

2. The chance of observing $\mathrm{FCu}$ fields over forest land cover increases with EVI (excluding very low or very high EVI values for specific years), and can generally be represented by a linear fit.

3. Up to a filter size of $25 \mathrm{~km}$, the $\mathrm{pFCu}$ dependence on EVI increases as we increase the spatial smoothing filter size of the EVI data.

4. The chance of observing FCu fields over non-forest land cover increases (decreases) for values lower (higher) than $\mathrm{EVI}=0.48$, and is generally lower than over forest land cover. However, the scattered spatial distribution of non-forest land cover (see Fig. 4a) and the strong correlation between non-forest EVI and meteorology cast doubt on the significance of this finding.

5. The dependence of $\mathrm{pFCu}$ on EVI in transition areas from non-forest/water boundaries into forested land cover can be expressed as a superposition of forest and non-forest dependencies. 
These findings show the strong control that land cover and land cover gradients exert on FCu. Even though the dependence need not be linear, EVI can be considered highly correlated with evapotranspiration, implying that high latent heat (moisture) fluxes are crucial for the development and organization of the $\mathrm{FCu}$ fields.

Nevertheless, elucidating the dynamical processes which are responsible for the formation of $\mathrm{FCu}$ field require future work. We can speculate that the $\mathrm{FCu}$ fields correspond to a specific solution of Rayleigh-Benard thermal convection over land (or specifically cloud streets, as discussed in Sect. 1), since the basic physical settings are similar over the Amazon and ocean surfaces, namely a homogeneous warm surface and a moist boundary layer with a well-defined inversion layer. Hexagonal open convection cells have already been simulated over tropical land in the western Pacific (Saito et al., 2001). The fact that vegetation properties control both surface fluxes and boundary layer depth $(h)$ to a large degree, and that the Rayleigh number $(R a)$ is highly dependent on that depth (proportional to $h^{4}$ ), suggests a physical link between forest and the cloud fields formed above.

As for climatic trends in Amazon cloud fields, it is hard to conclude how large-scale deforestation would affect total cloud cover since meteorological and land cover gradients roughly coincide in our study region. We can predict a reduction in dry season $\mathrm{FCu}$ fields as forest land cover undergoes transition to non-forest or as forest wellbeing decreases (reduction in EVI); however more extensive studies are needed to understand the total effect on the radiation budget and water cycle in the Amazon due to such changes.

Acknowledgements. This research was supported by the European Research Council under the European Union's Seventh Framework Programme (FP7/2007-2013)/ERC (CAPRI, grant no. 306965) and by a NASA Interdisciplinary Science (IDS) project managed by $\mathrm{H}$. Maring. We acknowledge the use of Rapid Response imagery (true color images in the work) from the Land Atmosphere Near-real time Capability for EOS (LANCE) system operated by the NASA/GSFC/Earth Science Data and Information System (ESDIS) with funding provided by NASA/HQ. Aerosol optical depth (AOD) data and visualizations (Fig. 6) were produced with the Giovanni online data system, developed and maintained by the NASA GES DISC.

Edited by: P. Stier

\section{References}

Ackerman, S. A., Strabala, K. I., Menzel, W. P., Frey, R. A., Moeller, C. C., and Gumley, L. E.: Discriminating clear sky from clouds with MODIS, J. Geophys. Res.-Atmos., 103, 3214132157, doi:10.1029/1998jd200032, 1998.

Amante, C. and Eakins, B. W.: ETOPO1 1 Arc-Minute Global Relief Model: Procedures, Data Sources and Analysis, NOAA Technical Memorandum NESDIS NGDC-24, doi:10.7289/V5C8276M, 2009.

Bastable, H. G., Shuttleworth, W. J., Dallarosa, R. L. G., Fisch, G., and Nobre, C. A.: Observations of Climate, Albedo, and Surface Radiation over Cleared and Undisturbed Amazonian Forest, Int. J. Climatol., 13, 783-796, doi:10.1002/joc.3370130706, 1993.

Betts, A. K.: Idealized model for equilibrium boundary layer over land, J. Hydrometeorol., 1, 507-523, doi:10.1175/15257541(2000)001<0507:Imfebl>2.0.Co;2, 2000.

Betts, A. K.: Land-Surface-Atmosphere Coupling in Observations and Models, J. Adv. Model Earth Syst., 1, 18 pp., doi:10.3894/James.2009.1.4, 2009.

Betts, A. K. and Silva Dias, M. A. F. S.: Progress in understanding land-surface-atmosphere coupling from LBA research, J. Adv. Model. Earth Syst, 2, 20 pp., doi:10.3894/JAMES.2010.2.6, 2010.

Brümmer, B.: Roll and cell convection in wintertime arctic coldair outbreaks, J. Atmos. Sci., 56, 2613-2636, doi:10.1175/15200469(1999)056<2613:RACCIW>2.0.CO;2, 1999.

Chagnon, F. J. F., Bras, R. L., and Wang, J.: Climatic shift in patterns of shallow clouds over the Amazon, Geophys. Res. Lett., 31, L24212, doi:10.1029/2004g1021188, 2004.

Cutrim, E., Martin, D. W., and Rabin, R.: Enhancement of Cumulus Clouds over Deforested Lands in Amazonia, B. Am. Meteorol. Soc., 76, 1801-1805, doi:10.1175/15200477(1995)076<1801:Eoccod>2.0.Co;2, 1995.

Figueroa, S. N. and Nobre, C. A.: Precipitation distribution over central and western tropical South America, Climanalise, 5, 3645,1990

Fisch, G., Culf, A. D., and Nobre, C. A.: Modelling convective boundary layer growth in Rondonia, in: Amazonian Deforestation and Climate, edited by: Gash, J. H. C., Nobre, C. A., Roberts, J. M., and Victoria, R. L., John Wiley \& Sons, Chichester, UK, 425-436, 1996.

Fisch, G., Tota, J., Machado, L. A. T., Dias, M. A. F. S., Lyra, R. F. D., Nobre, C. A., Dolman, A. J., and Gash, J. H. C.: The convective boundary layer over pasture and forest in Amazonia, Theor. Appl. Climatol., 78, 47-59, doi:10.1007/s00704-0040043-x, 2004.

Friedl, M. A., Sulla-Menashe, D., Tan, B., Schneider, A., Ramankutty, N., Sibley, A., and Huang, X. M.: MODIS Collection 5 global land cover: Algorithm refinements and characterization of new datasets, Remote Sens. Environ., 114, 168-182, doi:10.1016/j.rse.2009.08.016, 2010

Glenn, E. P., Huete, A. R., Nagler, P. L., and Nelson, S. G.: Relationship between remotely-sensed vegetation indices, canopy attributes and plant physiological processes: What vegetation indices can and cannot tell us about the landscape, Sensors-Basel, 8, 2136-2160, doi:10.3390/S8042136, 2008.

Glenn, E. P., Nagler, P. L., and Huete, A. R.: Vegetation Index Methods for Estimating Evapotranspiration by Remote Sensing, Surv Geophys., 31, 531-555, doi:10.1007/s10712-010-9102-2, 2010. 
Hansen, M., DeFries, R., Townshend, J. R., and Sohlberg, R.: Global land cover classification at $1 \mathrm{~km}$ spatial resolution using a classification tree approach, Int. J. Remote Sens., 21, 1331-1364, doi:10.1080/014311600210209, 2000.

Heiblum, R. H., Koren, I., and Altaratz, O.: Analyzing coastal precipitation using TRMM observations, Atmos. Chem. Phys., 11, 13201-13217, doi:10.5194/acp-11-13201-2011, 2011.

Huete, A., Didan, K., Miura, T., Rodriguez, E. P., Gao, X., and Ferreira, L. G.: Overview of the radiometric and biophysical performance of the MODIS vegetation indices, Remote Sens. Environ.t, 83, 195-213, doi:10.1016/S0034-4257(02)00096-2, 2002.

Juárez, N. R. I., Goulden, M. L., Myneni, R. B., Fu, R., Bernardes, S., and Gao, H.: An empirical approach to retrieving monthly evapotranspiration over Amazonia, Int. J. Remote Sens., 29, 7045-7063, 10.1080/01431160802226026, 2008.

Koren, I., Kaufman, Y. J., Remer, L. A., and Martins, J. V.: Measurement of the effect of Amazon smoke on inhibition of cloud formation, Science, 303, 1342-1345, doi:10.1126/science.1089424, 2004.

Koren, I., Martins, J. V., Remer, L. A., and Afargan, H.: Smoke invigoration versus inhibition of clouds over the Amazon, Science, 321, 946-949, doi:10.1126/science.1159185, 2008.

Lewis, S. L., Brando, P. M., Phillips, O. L., van der Heijden, G. M., and Nepstad, D.: The 2010 Amazon drought, Science, 331, p. 554, doi:10.1126/science.1200807, 2011.

Malda, D., Vilà-Guerau de Arellano, J., van den Berg, W. D., and Zuurendonk, I. W.: The role of atmospheric boundary layersurface interactions on the development of coastal fronts, Ann. Geophys., 25, 341-360, doi:10.5194/angeo-25-341-2007, 2007.

Martins, J. V., Tanre, D., Remer, L., Kaufman, Y., Mattoo, S., and Levy, R.: MODIS Cloud screening for remote sensing of aerosols over oceans using spatial variability, Geophys. Res. Lett., 29, 8009, doi:10.1029/2001g1013252, 2002.

Mu, Q., Heinsch, F. A., Zhao, M., and Running, S. W.: Development of a global evapotranspiration algorithm based on MODIS and global meteorology data, Remote Sens. Environ., 111, 519-536, doi:10.1016/j.rse.2007.04.015, 2007.

Nagler, P. L., Scott, R. L., Westenburg, C., Cleverly, J. R., Glenn, E. P., and Huete, A. R.: Evapotranspiration on western US rivers estimated using the Enhanced Vegetation Index from MODIS and data from eddy covariance and Bowen ratio flux towers, Remote Sens. Environ., 97, 337-351, doi:10.1016/j.rse.2005.05.011, 2005

Nair, U. S., Lawton, R. O., Welch, R. M., and Pielke Sr, R. A.: Impact of land use on Costa Rican tropical montane cloud forests: Sensitivity of orographic cloud formation to deforestation in the plains, J. Geophys. Res., 111, D02108, doi:10.1029/2005JD006096, 2003.

Nobre, C. A., Mattos, L. F., Dereczynski, C. P., Tarasova, T. A., and Trosnikov, I. V.: Overview of atmospheric conditions during the Smoke, Clouds, and Radiation - Brazil (SCAR-B) field experiment, J. Geophys. Res.-Atmos., 103, 31809-31820, doi:10.1029/98jd00992, 1998.

Parrish, D. F. and Derber, J. C.: The National Meteorological Center's spectral statistical-interpolation analysis system, Mon. Weather Rev., 120, 1747-1763, doi:10.1175/15200493(1992)120<1747:TNMCSS>2.0.CO;2, 1992.
Pielke Sr, R. A., Pitman, A., Niyogi, D., Mahmood, R., McAlpine, C., Hossain, F., Goldewijk, K. K., Nair, U., Betts, R., and Fall, S.: Land use/land cover changes and climate: modeling analysis and observational evidence, Wiley Interdisciplinary Reviews: Climate Change, 2, 828-850, doi:10.1002/wcc.144, 2011.

Rabin, R. M., Stadler, S., Wetzel, P. J., Stensrud, D. J., and Gregory, M.: Observed Effects of Landscape Variability on Convective Clouds, B. Am. Meteorol. Soc., 71, 272-280, doi:10.1175/15200477(1990)071<0272:Oeolvo>2.0.Co;2, 1990.

Ramos da Silva, R., Gandu, A. W., Sá, L. D. A., and Silva Dias, M. A. F.: Cloud streets and land-water interactions in the Amazon, Biogeochemistry, 105, 201-211, doi:10.1007/s10533-011-95804, 2011

Ray, D. K., Nair, U. S., Welch, R. M., Han, Q. Y., Zeng, J., Su, W. Y., Kikuchi, T., and Lyons, T. J.: Effects of land use in Southwest Australia: 1. Observations of cumulus cloudiness and energy fluxes, J. Geophys. Res.-Atmos., 108, 4414, doi:10.1029/2002jd002654, 2003.

Remer, L. A., Kaufman, Y. J., Tanre, D., Mattoo, S., Chu, D. A., Martins, J. V., Li, R. R., Ichoku, C., Levy, R. C., Kleidman, R. G., Eck, T. F., Vermote, E., and Holben, B. N.: The MODIS aerosol algorithm, products, and validation, J. Atmos. Sci., 62, 947-973, doi:10.1175/Jas3385.1, 2005.

Running, S. W., Justice, C. O., Salomonson, V., Hall, D., Barker, J., Kaufmann, Y. J., Strahler, A. H., Huete, A. R., Muller, J. P., Vanderbilt, V., Wan, Z. M., Teillet, P., and Carneggie, D.: Terrestrial Remote-Sensing Science and Algorithms Planned for Eos Modis, Int. J. Remote Sens., 15, 3587-3620, doi:10.1080/01431169408954346, 1994.

Saha, S., Nadiga, S., Thiaw, C., Wang, J., Wang, W., Zhang, Q., Van den Dool, H. M., Pan, H. L., Moorthi, S., Behringer, D., Stokes, D., Pena, M., Lord, S., White, G., Ebisuzaki, W., Peng, P., and Xie, P.: The NCEP Climate Forecast System, J. Climate, 19, 3483-3517, doi:10.1175/Jcli3812.1, 2006.

Saito, K., Keenan, T., Holland, G., and Puri, K.: Numerical Simulation of the Diurnal Evolution of Tropical Island Convection over the Maritime Continent, Mon. Weather Rev., 129, 378-400, doi:10.1175/1520-0493(2001)129<0378:NSOTDE>2.0.CO;2, 2001.

Salomonson, V. V., Barnes, W. L., Maymon, P. W., Montgomery, H. E., and Ostrow, H.: Modis - Advanced Facility Instrument for Studies of the Earth as a System, IEEE T. Geosci. Remote, 27, 145-153, doi:10.1109/36.20292, 1989.

Sjöström, M., Ardö, J., Arneth, A., Boulain, N., Cappelaere, B., Eklundh, L., de Grandcourt, A., Kutsch, W. L., Merbold, L., and Nouvellon, Y.: Exploring the potential of MODIS EVI for modeling gross primary production across African ecosystems, Remote Sens. Environ., 115, 1081-1089, doi:10.1016/j.rse.2010.12.013, 2011.

Souza, E. P., Renno, N. O., and Dias, M. A. F. S.: Convective circulations induced by surface heterogeneities, J. Atmos. Sci., 57, 2915-2922, doi:10.1175/1520 0469(2000)057<2915:Ccibsh>2.0.Co;2, 2000.

Ten Hoeve, J., Remer, L., Correia, A., and Jacobson, M.: Recent shift from forest to savanna burning in the Amazon Basin observed by satellite, Environ. Res. Lett., 7, 024020, doi:10.1088/1748-9326/7/2/024020, 2012. 
Wang, J., Chagnon, F. J., Williams, E. R., Betts, A. K., Renno, N. O., Machado, L. A., Bisht, G., Knox, R., and Bras, R. L.: Impact of deforestation in the Amazon basin on cloud climatology, Proc. Natl. Acad. Sci. USA, 106, 3670-3674, doi:10.1073/pnas.0810156106, 2009.
Xiao, X. M., Braswell, B., Zhang, Q. Y., Boles, S., Frolking, S., and Moore, B.: Sensitivity of vegetation indices to atmospheric aerosols: continental-scale observations in Northern Asia, Remote Sens. Environ., 84, 385-392, doi:10.1016/S00344257(02)00129-3, 2003. 